\title{
Developing an Intelligent Recommendation System for Course Selection by Students for Graduate Courses
}

\section{Grewal DS ${ }^{1 *}$ and Kaur K}

${ }^{1}$ Research \& Development, Desh Bhagat University, Mandi Gobindgarh, Ludhiana, India ${ }^{2}$ Guru Nanak Dev Engineering College, Ludhiana, India

\begin{abstract}
Choosing a right course in formative years is very important decision as his future depends on this one decision. Student by himself is not mature enough to take right decision in his early life. Selecting wrong courses means mismatch between student aptitude, capability and personal interest. Faculty or parents have neither the required knowledge nor experience. Since there is no other reliable source generally available that can guide the student towards the most suitable direction, recommender system has been evolved to provide him guidance in selecting a right course. Recommender system is a computer programme prepared with the help of experts where the details of background of the students and their aptitudes help finding a course for his future study. This paper proposes feasible predictions for student's course selection based on their marks and choice of job interest. Clustering technique is used to find structures and relationship within the data. This paper also reveals the research process of preparation of such a recommender system.
\end{abstract}

\section{Keywords: Recommender system; Courses; Clustering technique}

\section{Introduction}

The primary purpose of this research article is to discover the influence of career discovery. The module is a computer- assisted program for career decision making on the basis of marks and choice. The targeted population for this study was $10+2$ passed students eager to join various fields like engineering, medical, commerce, arts etc. while for testing the system reliability students who have already made the choice were considered. A sample of this accessible population was drawn through random sampling procedures.

Provision of career counselling services is one of the main factors furnishing students' academic success. Main feature of student utilities is to give them the course best suited for their future and matches his attitude and attribute. Students chose particular courses of study because of perceived job opportunities, their interests and the likely future developments at the time of his completion of course. Problems arise if a student is not interested in the course or if career is not perfectly matching the student's capability [1-4].

Student counselling must include opinion on career guidance, handling inter-personnel relation, qualities of learning strategies and also the attitude and aptitude. Normally this activity is provided by counsellors or advisors who have lots of experience in the organisation. But with growing number of students and number of choices, and the amount of work on these advisors who are not able to handle the situation, the faculty of education institutions at higher secondary level does not have sufficient knowledge and experience of the courses and programmes except that of education. They also do not have time to counsel their students due to workload. Hence it is desirable to have some form of intelligent recommendation tools that needed to be developed to help them in the process of admissions. This problem determined the inspiration for this research and for developing the recommender system to help students and staff. This system is recommended to be used to collect course information and counselling for an entrant to a course to cope up between his capabilities and future requirements.

\section{Requirement of Recommendation System (RS)}

The focus of this recommendation system is on $10+2$ students of all streams. A recommendation system could apply statistical, artificial intelligence and data mining techniques to the problem of making suitable recommendation for the students. Related to educational institutes, the students are considered as "customers" and the goal of Student Relationship Management is to satisfy them and commitments for the improvement of the institute. RS aims at growing and maintaining a joint relationship between the institute and the students by helping the student to choose right course that matches with his job interest. Piedade and Santos [5-7] explained that Student Relationship Management (SRM) involves the Association of proceeding indicators and behavioural design that describe the students and distinct conditions for the supervision. Adding to this, the meaning of SRM is "To understand student acquired knowledge based process, which fulfils the aim of close relationship between students and institutions by observing both academic activities and academic path. SRM can be used for significant purpose for upholding and enhancement of student's satisfaction [8]. To comprehend the necessity of the student is necessary for their fulfilment of needs. It is essential to prepare strategies in both teaching and related services to maintain Student Relationship Management. The importance of evolving a strong connection between university and student is a long term goal.

\section{Problems Faced by Students}

During their time in the universities the problems faced by students and issues are many. For example, depression is common problem among some students. It affects the student behaviour as regard to their experience and the student's inspiration, concentration,

*Corresponding author: Grewal DS, Dean Research \& Development, Desh Bhagat University, Mandi Gobindgarh, India, Tel: 082838 11111; E-mail: dalvinder45@yahoo.co.in

Received March 15, 2016; Accepted March 30, 2016; Published April 06, 2016

Citation: Grewal DS, Kaur K (2016) Developing an Intelligent Recommendation System for Course Selection by Students for Graduate Courses. Bus Eco J 7: 209. doi:10.4172/2151-6219.1000209

Copyright: (c) 2016 Grewal DS, et al. This is an open-access article distributed under the terms of the Creative Commons Attribution License, which permits unrestricted use, distribution, and reproduction in any medium, provided the original author and source are credited. 
feeling of self-worth, and mood [9]. From the perspective of the university, the issues are related to allotment of resources and how to recruit students of high competence and who have high probability of completion. If management decisions are not made properly, this could lead to unfulfilled number places and loss of potential tuition fees. The problem of student retention in higher education can further give rise to low student contentment; student movement from one place to another and dropping-out [10]. It may cause problem of loss of students and source of income, and elevated cost of replacement. However, it was also noticed that other factors that impress students to change educational institutes in higher education are the quality and convenience of support services [11]. So, to recruit and enrol students in higher education, it is absolutely necessary to fulfil the student's needs and to fit to their ability. To know the student's needs will enlarge the student's knowledge acquiring experience and greater chances of success, and reduce loss of resources due to retract, and change of programs.

\section{Current Solutions}

Inferring the working information systems helps student management, student services and market operation for the part taker. It is necessary to elaborate tactics to preserve and improve student satisfaction which is main aim of Student Recommender System (SRS). Some relevant plans on explanation for the university management and students samples of solutions are given here. Junnutula and Tengyan [12] offers online study and recommendation system which enhance the system to employ group and individual learning process which provide supporting activity with several features. They recommend online courses.

The provision of counselling and successful professional services is another approach accepted by universities. To achieve the institution's mission, the necessary helpful activity provided by universities are psychological counselling, professional and work-arrangement opinion and money matters support. In addition, feedback from students is of critical importance. In term of education systems, Ackerman and Schibrowsky [13] have used the idea of business involvement and offered the business involving marketing framework. The design satisfies a distinct vision on retaining capacity strategies and an economic explanation for the fulfilment of retaining programs. This framework is appropriate both on the issues of quality of services.

\section{Survey of Related Literature}

Kuyoro, et al. published optimal algorithm suitable for predicting students academic performance, designing a framework of intelligent recommender system that can predict students' performance as well as recommend necessary actions to be taken to aid the students and identifying background factors that affect students' academic performance in tertiary institution at the end of first year. Research used ten classification models and a multilayer perception; an artificial neural network function generated using Waikato Environment for Knowledge Analysis (WEKA). The work shows that identifying the relevant student background factors can be incorporated to design a framework that can serve as valuable tool in predicting student performance as well as recommend the necessary intervention strategies to adopt.

Nguyen, et al. and others proposed a novel approach which uses recommender system techniques for educational data mining, especially for predicting student performance. They compare recommender system techniques with traditional regression methods such as logistic/ linear regression by using educational data for intelligent tutoring systems. Experimental results show that the proposed approach can improve prediction results.

Kanokwan suggests that in Thailand, choosing a program of study for tertiary students is significant due to future job opportunities. Many students have enrolled in course majors without receiving counselling or advices from appropriate authorities or university services. This could be the mismatch between students' aptitude, personal interest and capability, and the particular course being taken up. This may lead to low retention rate and failures. In order to improve and support the academic management processes, many universities in Thailand are developing innovative information systems and services with an aim to enhance efficiency and student relationship. Some of these initiatives are in the form of a Student Recommendation System (SRM). This paper reports a study on an investigation of possible correlation between student historic data and their final results. Clustering techniques have been used with the aim to find structures and relationship within the data. Results from two clustering methods, k-means and Two-Step methods had been compared. The paper described the development of the experiments, and the proposed Intelligent Recommendation System framework.

Queen Esther Booker designed a system that could essentially perform a pre-selection program plan for prospective students that would give them a potential road-plan for an academic career at Minnesota State University, Mankato. Study grew from inquiries from students who learned about the Management Information Systems (MIS) major too late in their academic careers to switch into the program, and from students who had taken the wrong pre-requisites to enrol in the MIS upper division courses and thus resorted to another major. From these inquiries, they help students identify a program that matches their interests earlier in their academic careers which potentially reduce attrition, increase student satisfaction and improve recruitment for the university.

\section{Research Gaps}

The recommender system makes use of very large matrices whose space complexity is $\mathrm{O}(\mathrm{mn})^{\mathrm{k}}$. So the calculations require a great amount of storage space and disk space and memory. Due to Restricted Space and Network bandwidth, alternatives have to be found to work within the limitations.

\section{Research Design}

Research will be experimental in nature. Algorithms will be used for designing the computer programmes for a Recommender System. It will involve:

\section{(a) Data Collection}

(b) Data Segregation

(c) Data analysis

(d) Defining Feature Vector

(e) Creating Feed-Forward Back-Propagation Probabilistic Neural network

(f) Train Neurons

(g) Comparing with Existing Art

\section{Need of the study}

There are various algorithms proposed in the literature, most of 
them trying to improve using K-means algorithm because K-means algorithm is easier to understand and it is very simple to implement. The simpler the algorithm, the better it will perform for example in image compression technique JPEG 2000. K-means is continuous algorithm and works better if data set is continuous in nature. But this is not in case of recommendation because the nature of items is discrete and researcher tends to use Euclidean Distance which is computationally very expensive since it requires both power and square root functions. Both of these functions require more than 200 cycles to complete. The situation gets worse when they have to perform these functions over a large dataset. This very large calculation is performed only for one request for recommendation. But large business concern has to handle millions of these requests per day. Similarly, a recommender system with a need of some efficient algorithms for computation of large data is needed for providing right options to the $10+2$ students a research is needed to prepare such a system. This work focuses on developing a recommender system based on Feed-forward back propagation probabilistic neural network whose running time is better than the recommender based on K-means algorithm or other neural network.

\section{Objectives}

1. To work out the requirements of recommender Systems for Educational Guidance

2. To design and develop a Recommender System on Counselling in Technical Education Field.

3. To design and develop a new Recommender System with running time better than the others mentioned in the literature.

\section{Methodology}

1. Gather the source data required. data.

2. Organise the data in required format and remove unimportant

3. Derive few conclusions using small engine.

4. Based on conclusion data a feature vector and data is defined.

5. Give input to input layer of Neural Network.

6. Process data in hidden layer of neural network.

7. Match output to desired result.

8. If it matches then display subset of data and if does not match then adjust weights.

\section{Parameters}

Include (a) student preference, (b) previous results, (c) scores of each subject and the (d)overall percentage from the entire database, (e) Job Interest and (f) Feedback.

\section{Tools}

Hardware: 12.1.1 Pc (CPU 2.0 Ghz, ram 4 gb, Hardisk 40 gb of free space)

Software and libraries: 12.2.1 PHP, MySql and python

Samples: Data of 1500 students will be obtained from engineering stream.

\section{Desiging the Program}

\section{Proposed architecture of recommendation system}

A recommendation system can employ data mining, statistical and artificial intelligence techniques to make appropriate recommendation for the students. A framework is given out here considering the requirements and need of the study.

\section{Framework}

This framework used these techniques: Clustering Technology, Feed-forward back propagation probabilistic neural network and Classification using Fuzzy Logic and Rough Set. It was categorized into three phases: Data Preparation, Data Analysis and Predictive Modelling, training and testing data. A sample data is trained and tested using Feed-forward back propagation probabilistic neural network. It includes the background to include (a) student preference, (b) previous results, (c) scores of each subject and (d) the overall percentage from the entire database. The result produced is then compared with the bio-data of the student to be admitted. The recommendation system then provides the most appropriate courses and subjects for students (Figure 1).

\section{Language used for programming}

Language used is PHP and mySql

\section{Data preparation}

Data is collected on the Performa given at annexure. The data collected is formatted and fed into the computer for the purpose of data transformation in respective parameters. The parameters used in the data are investigated and analysed and the absent data is handled intelligently. [14].

\section{Data analysis}

Clustering Techniques such as K-Means Clustering Algorithm was applied to group the data [15]. Clustering is used for classification of the required student's data and the acts performed are aligned into the meaningful division of groups based on previous data. The set of data items from the clustering process is then trained and tested by optimizing the error. Association rule is then used to inspect the association linking the subgroups $[16,17]$. This process is then applied to find out the student characteristics that align the individual characteristics. The Association Rule provides the number of occurrences that it

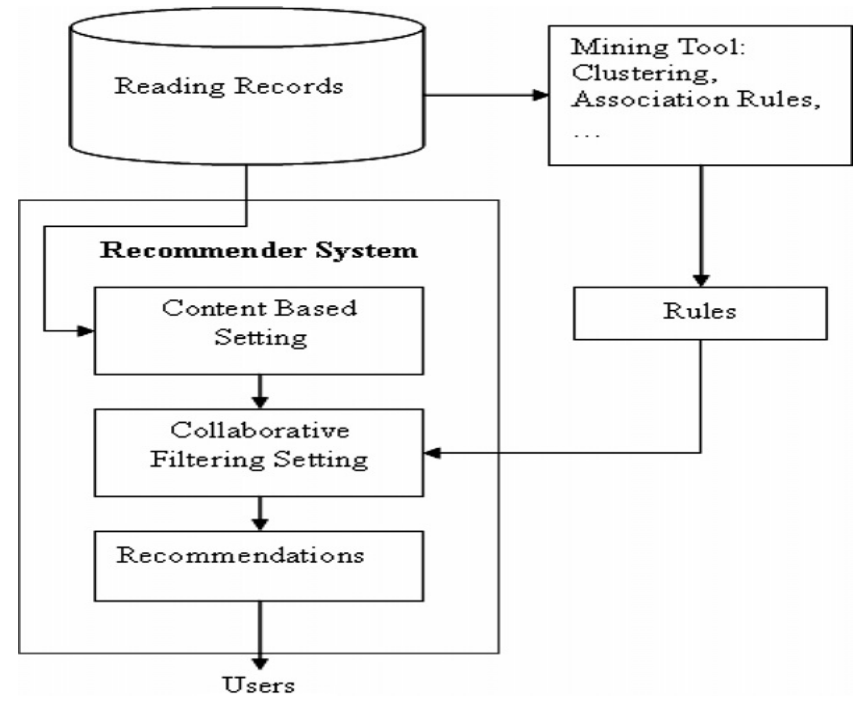

Figure 1: A simple architecture of the recommender system. 
predicts correctly [15]. The general output is observed comparing the difference with the clustering output to make the prediction more correctly. The classification based on Fuzzy set theory and Rough Set is applied [18]. Fuzzy set has been used for representing knowledge and decision making. Fuzzy system constitutes of four basic modules which are fuzzification unit, inference module, fuzzy rule based and de-fuzzification unit. The process, data is then chosen through selective sampling process and the classification rules are deduced from the training set.

For example, a simple fuzzy rule is written as:

If GPA="A" and Interested Subject 1="Science" and interested

subject $2=$ "Computers" then recommend="Computers".

To validate the accuracy of the rules from the training data set, an independent testing data set has been applied. The important thing at this stage is the requirements to gather efficient training set to create classified rules. Rough set is used to find the minimal subsets of attributes and they are applied to data with different categorical values. Various parameters used in the data analysis were identified and the data not found is managed [19].

\section{Prediction model}

The predictions made include an interrelated process which calculates the outputs from the previous stage and applies a weighted formula to determine the conclusive recommendation. The weights are determined from prior well known data and subject to human interference inference from heuristic knowledge of the advisor or tutor.

\section{Application program}

The developed model was tested live in Punjab on 1500 students checking the validity and reliability. The students were given the form to fill and with the help of programme the course which was most suitable after completing $10+2$ was selected through the computer program. The recommender system designed suggests suitable information based on courses, jobs and activities to uphold student's decision. At last students were required to make final decision related to their studies.

\section{Experimentation}

\section{Students' streams}

All students were grouped in to various streams and courses like Physics, Chemistry and Mathematics (PCM), Physics, Chemistry and Medical (PCB), Commerce Arts and sub streams as shown in the diagram below (Figure 2).

\section{Data preparation}

The data prepared and selected employed a dataset of 1500 student from various academic years. All student data include records from various years. Concentrating on required data only, no personal data is involved so that no student can be identified individually in this research, keeping the matter confidential. Random data is selected from whole database and all private information is deleted. After the process of data collection, data is reformatted in the data transformation stage. In cleaning process selected parameters are used in data analysis and incomplete data is removed. The student records are dissociated into different cases and each case is dissociated into training and testing data sets. Then average cluster distance is calculated within each cluster.

\section{Student recommendations}

Student registration: Student have to enter his personal details. Details include Name, Father's name, Date of Birth,School Name,

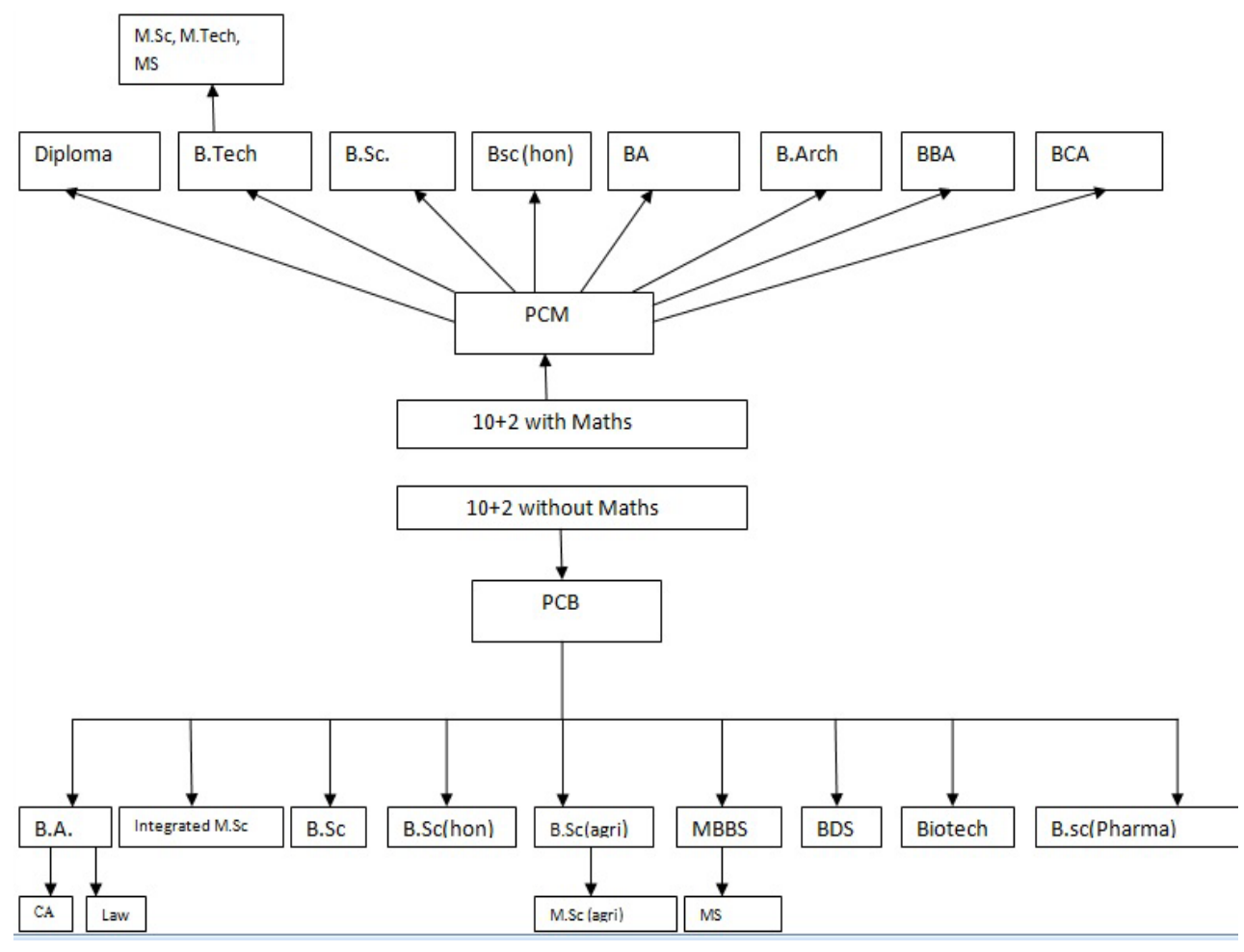

Figure 2: Showing streams and sub-streams and courses for $10+2$ students. 
Board of Study, Date of passing $12^{\text {th }}$, Roll No, Email and Password. Student have to remember Email and password. These fields are required for login into the system (Figure 3).

Student login: Once registered student can login anytime.
Students can view options available for his career. Students have to fill his username and password to proceed further (Figure 4).

Choose Stream in $12^{\text {th }}$ class (Figure 5).

If student chooses ARTS stream, options in chart will appear. He/

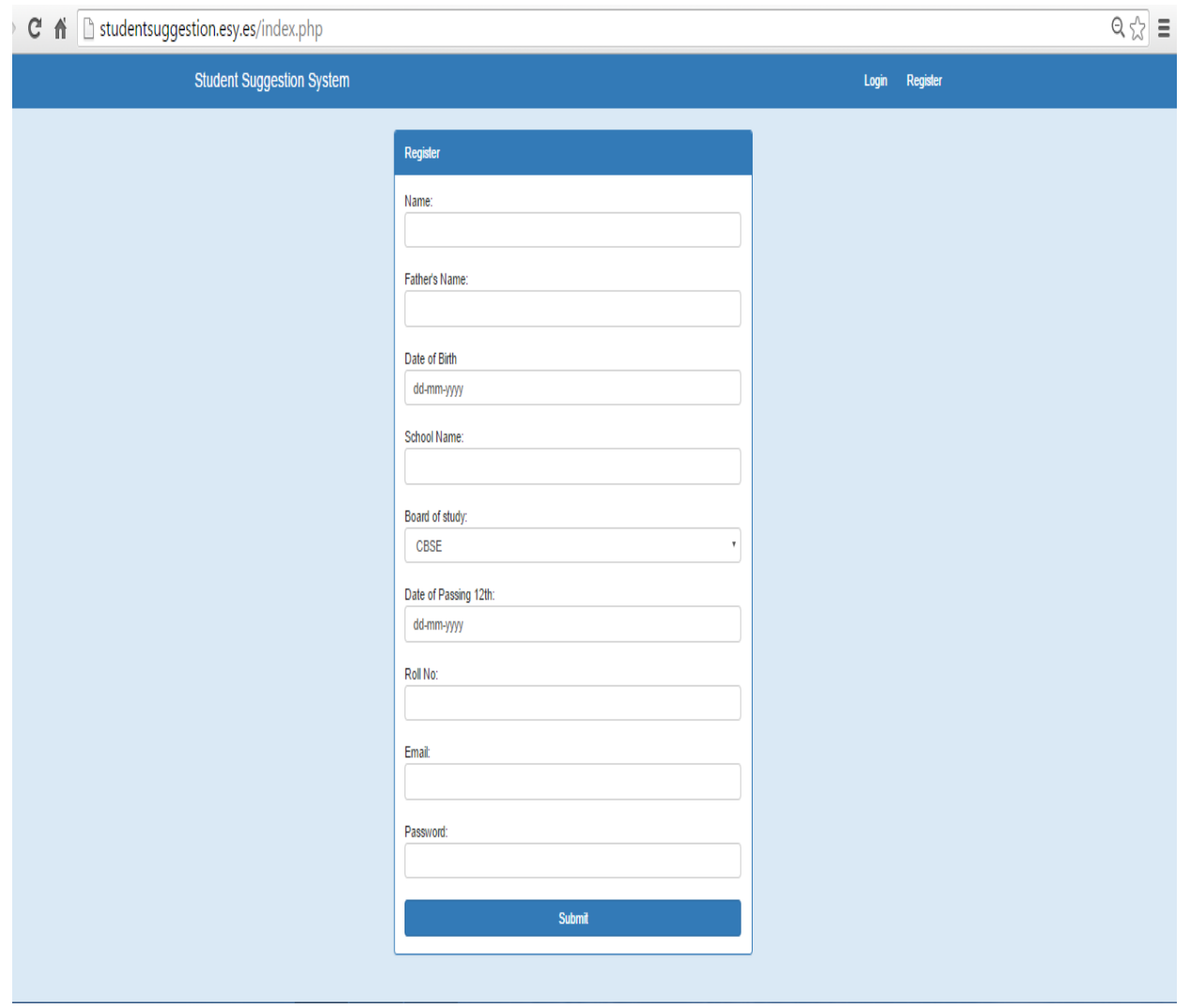

Figure 3: Student registration.

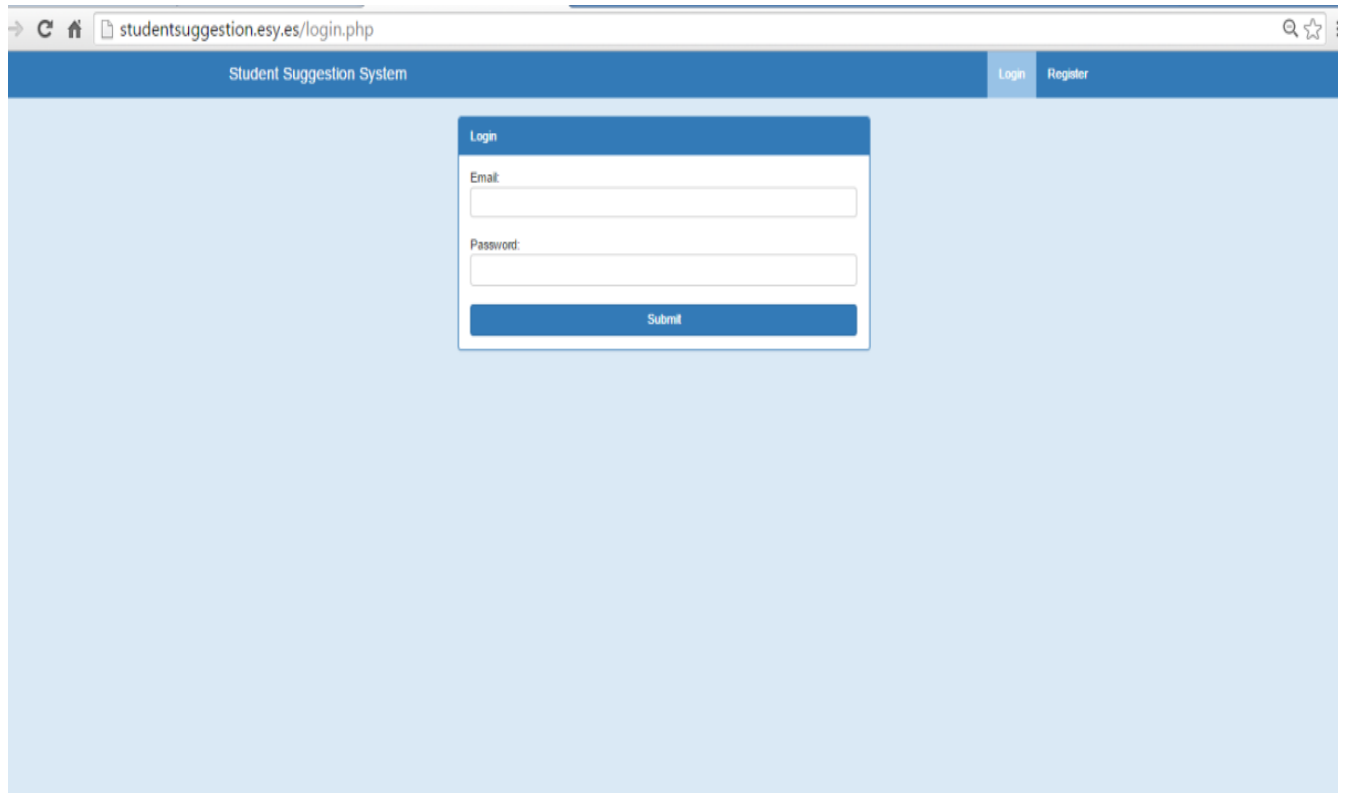

Figure 4: Student login. 
She have to enter marks in the five opted subjects. (Figure 6).

Suggestions based on all five subjects (Figure 7).

Suggestions are shown on basis of overall percentage. (Figure 8).
Then proceed further to choose job interest (Figure 9).

Student will Choose his job interest. He can click on any number of options. Then click button to generate final suggestion.

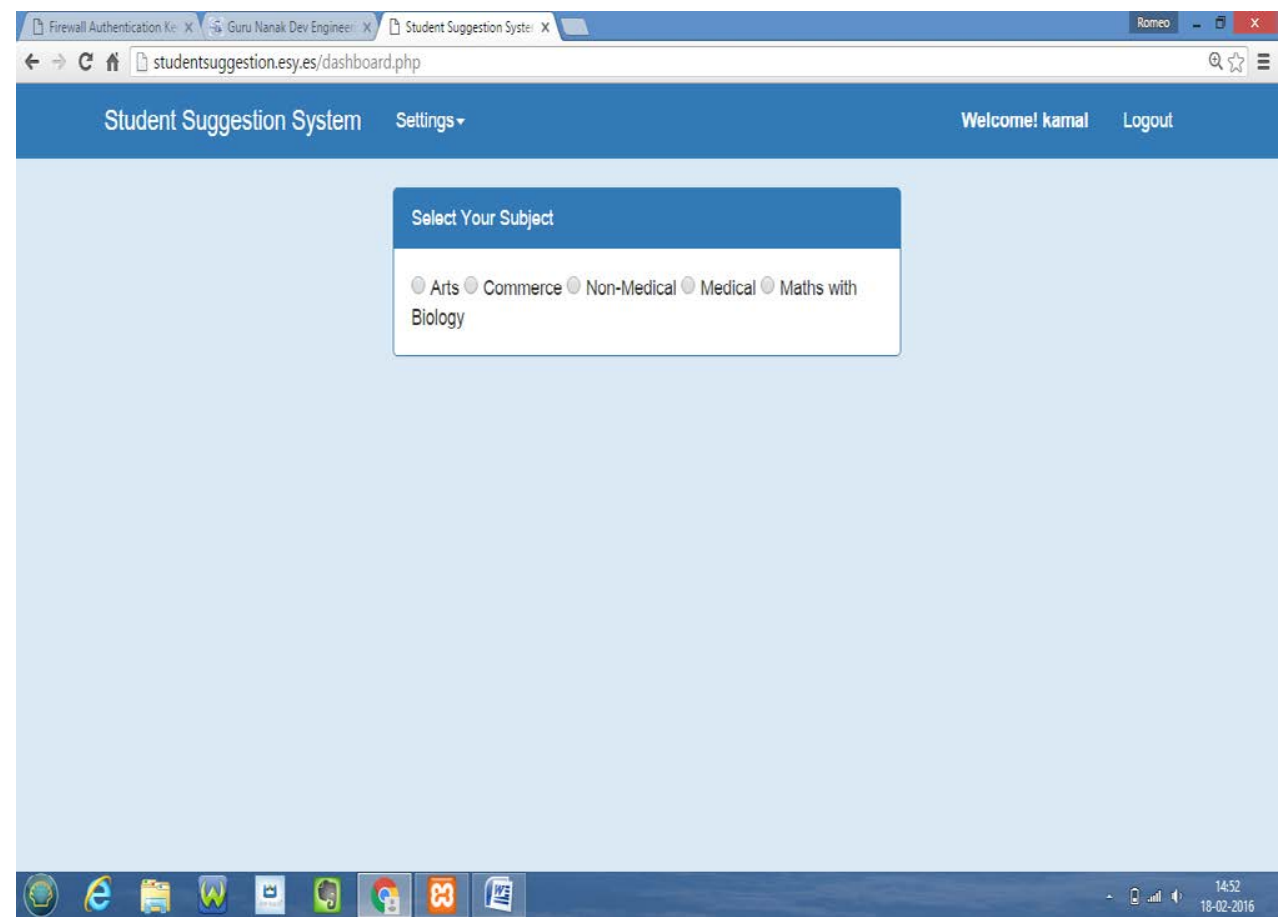

Figure 5: Choosing stream.

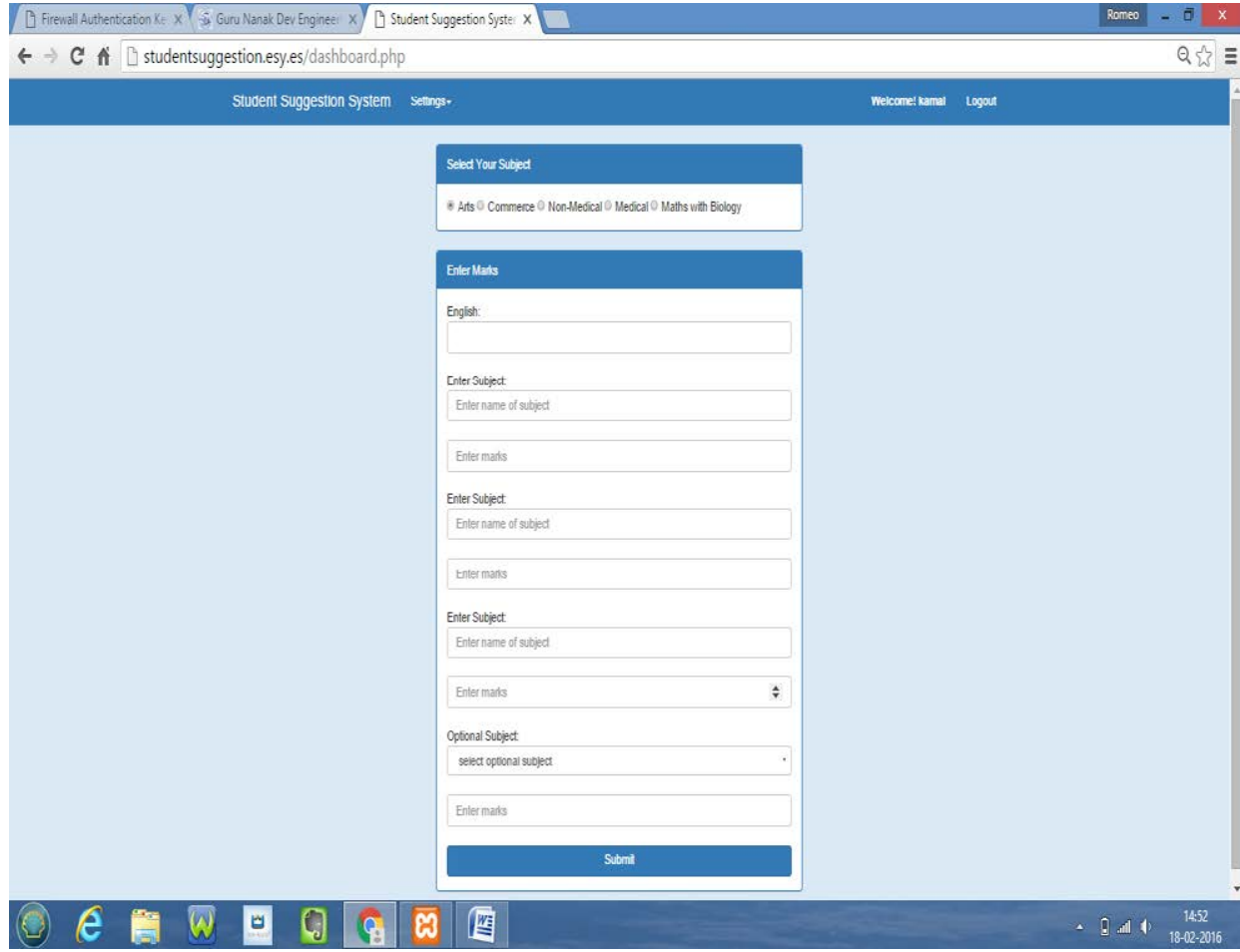

Figure 6: Options in chart. 


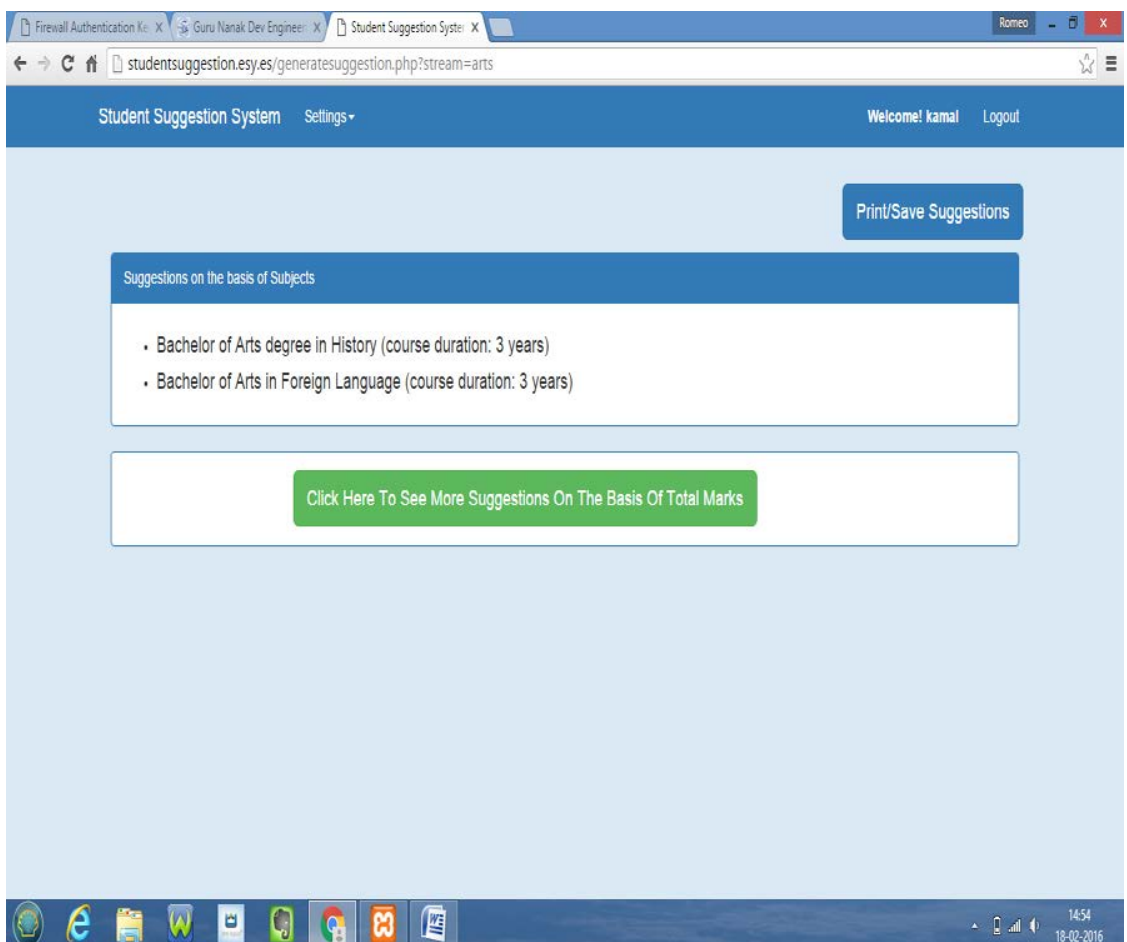

Figure 7: Suggestions based on all five subjects.

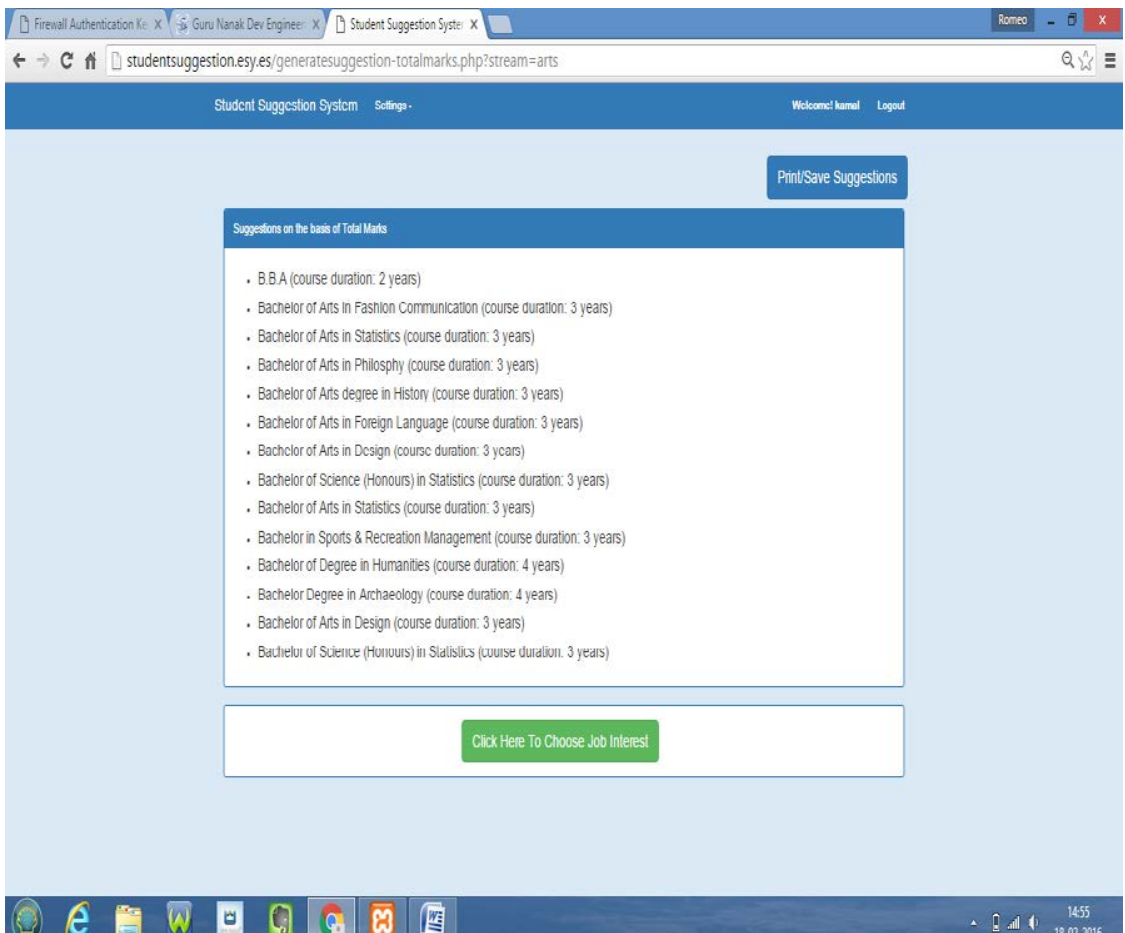

Figure 8: Suggestions are shown on basis of overall percentage.

Final suggestions on the basis of overall marks and Job interest is generated.

Students can take Print out of these suggestions. He can edit the marks. After completing this process student will Logout of the system. Then again fill his username and password and fill the feedback form (Figure 10). 


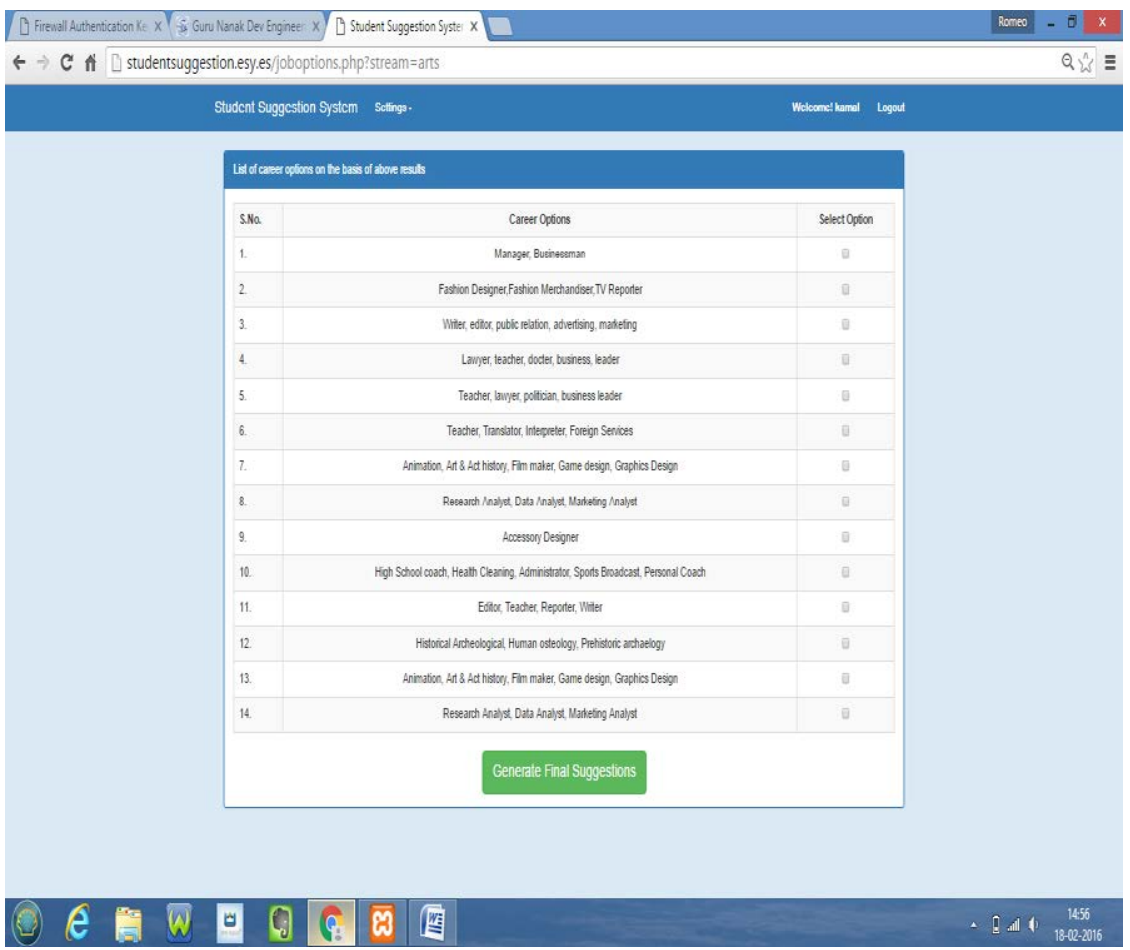

Figure 9: Choose job interest.

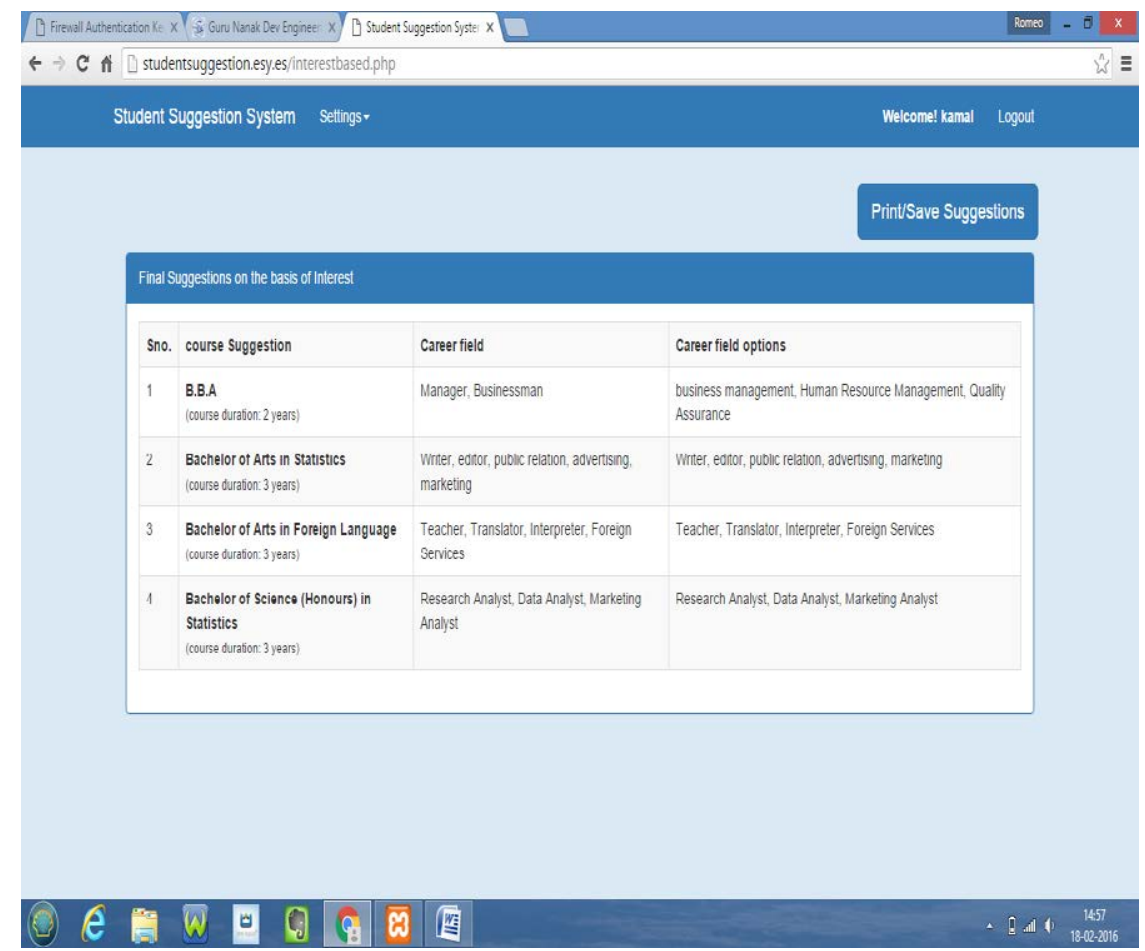

Figure 10: Feedback form.

\section{Result and Analysis}

\section{Validity}

The students were given the form to fill and with the help of programme the course which was most suitable after completing $10+2$ was selected through the computer program. Students' satisfaction was seen in 95\% cases. The recommender system designed suggested suitable information based on courses, jobs and activities to uphold 
Citation: Grewal DS, Kaur K (2016) Developing an Intelligent Recommendation System for Course Selection by Students for Graduate Courses. Bus Eco J 7: 209. doi:10.4172/2151-6219.1000209

Page 9 of 9

student's decision. At last students were able to make final decision related to their studies. Feedback form was filled by the students, in which they gave special comments. The data of students who joined various courses in previous years was also fed into computer and results were compared with the ones already achieved and the satisfaction level in these courses.

\section{Reliability}

The results given by the programme were compared with the students' choices in previous years and their satisfaction level and found reliable meeting the user requirement and satisfaction level of the students in their desired courses.

\section{Recommendations}

Recommender Systems for Educational Guidance is essentially required for helping students to select the courses of their choice. A recommendation system has been designed and developed as a Recommender System on Counselling in Technical Education Field and has been found effective. This new Recommender System provided better running time than the other systems mentioned in the literature. This system is recommended to be extended for other selection systems as well.

\section{Conclusion}

The paper presents Student Recommender System for matters associated to the problem of course selection for $10+2$ students in all streams and provides effective advice and counselling for them. System is developed and tested; the prediction model is precise. The recommendation system will be a helpful for students to establish College Student Relationship Management strategy as well.

\section{References}

1. Tejeda-Lorente A, Porcel C, Peis E, Sanz R (2014) A quality based recommender system to disseminate information in a university digital library. Information Sciences 261: 52-69.

2. Bobadilla J, Serradilla F, Hernando A (2009) Collaborative filtering adapted to recommender systems of e-learning. Knowledge-Based Systems 22: 261-265.

3. Bell RM (2007) Scalable collaborative filtering with jointly derived neighbourhood interpolation weights. Proceedings of the $7^{\text {th }}$ IEEE International Conference on Data Mining (ICDM'07), IEEE CS, Washington, USA, 43-52.
4. Bekele R, Menzel W (2005) A bayesian approach to predict performance of a student (bapps): a case with ethiopian students. Artificial Intelligence and Applications, Vienna, Austria, 189-194.

5. Cen H, Koedinger K, Junker B (2006) Learning Factors Analysis A Genera Method for Cognitive Model Evaluation and Improvement. Intelligent Tutoring Systems 4053 Springer Berlin Heidelberg, 164-175.

6. David C, David BW, Bramley LR (2000) Case-based recommender components for scientific problem-solving environments.16th IMACS World Congress.

7. Ge L, Kong W, Luo J (2006) Courseware recommendation in e-learning system. $5^{\text {th }}$ International Conference on Web-based Learning, 10-24.

8. Ghauth $\mathrm{Kl}$, Abdullah N (2010) Learning materials recommendation using good learners. Educational Technology Research and Development, 58: 711-727.

9. Linden G, Smith B, York J (2003) Amazon.com recommendations: item-to-item collaborative filtering. IEEE internet Computing 7.

10. Garcia E, Romero C, Ventura S, Castro CD (2011) An architecture for making recommendations to courseware authors using association rule mining and collaborative filtering. User Modelling and User-Adapted Interaction 19: 99-132.

11. Herlocker JL, Konstan JA, Terveen LG, Riedl JT (2004) Evaluating collaborative filtering recommender systems. ACM Transactions on Information Systems 22: 5-53.

12. Jain AK (2010) Data clustering: 50 years beyond K-means, Pattern recognition Letters. 31: 651-666.

13. Jain AK MN, Murty, Flynn PJ (1999) Data Clustering: A Review. ACM Computing Surveys 31.

14. Reddy JM, Wang T (2014) Online Study and Recommendation System. Fina report ACM 1-8.

15. Kyoto O, Shade, Samuel, Nicolae G (2013) Framework of recommendation system for tertiary institution. International Journal of Computer and Information Technology 2: 648-657.

16. Koren Y, Bell R, Volinsky C (2009) Matrix Factorization Techniques for Recommender Systems. IEEE Computer Society Press 42: 30-37.

17. Ricci F, Rokach L, Shapira B, Kantor PB (2011) 1st Recommender Systems Handbook, Springer-Berlin, 1-29.

18. Khribi MK, Jemni M, Nasraoui O (2008) Automatic Recommendations for E-Learning Personalization Based on Web Usage Mining Techniques and Information Retrieval. 8th IEEE International Conference on Advanced Learning Technologies, IEEE Computer Society, 241-245.

19. Kongsakun K, Fung CC, Chanakul T (2010) Developing an intelligent recommendation system for a private university in Thailand. Issues in Information Systems, 11: 467-472. 